\title{
Сборка СвЧ-модулей: SMD-монтаж и микроэлектронные технологии на одной площадке
}

Визит на сборочное производство АО «Микроволновые системы» В. Миронюк
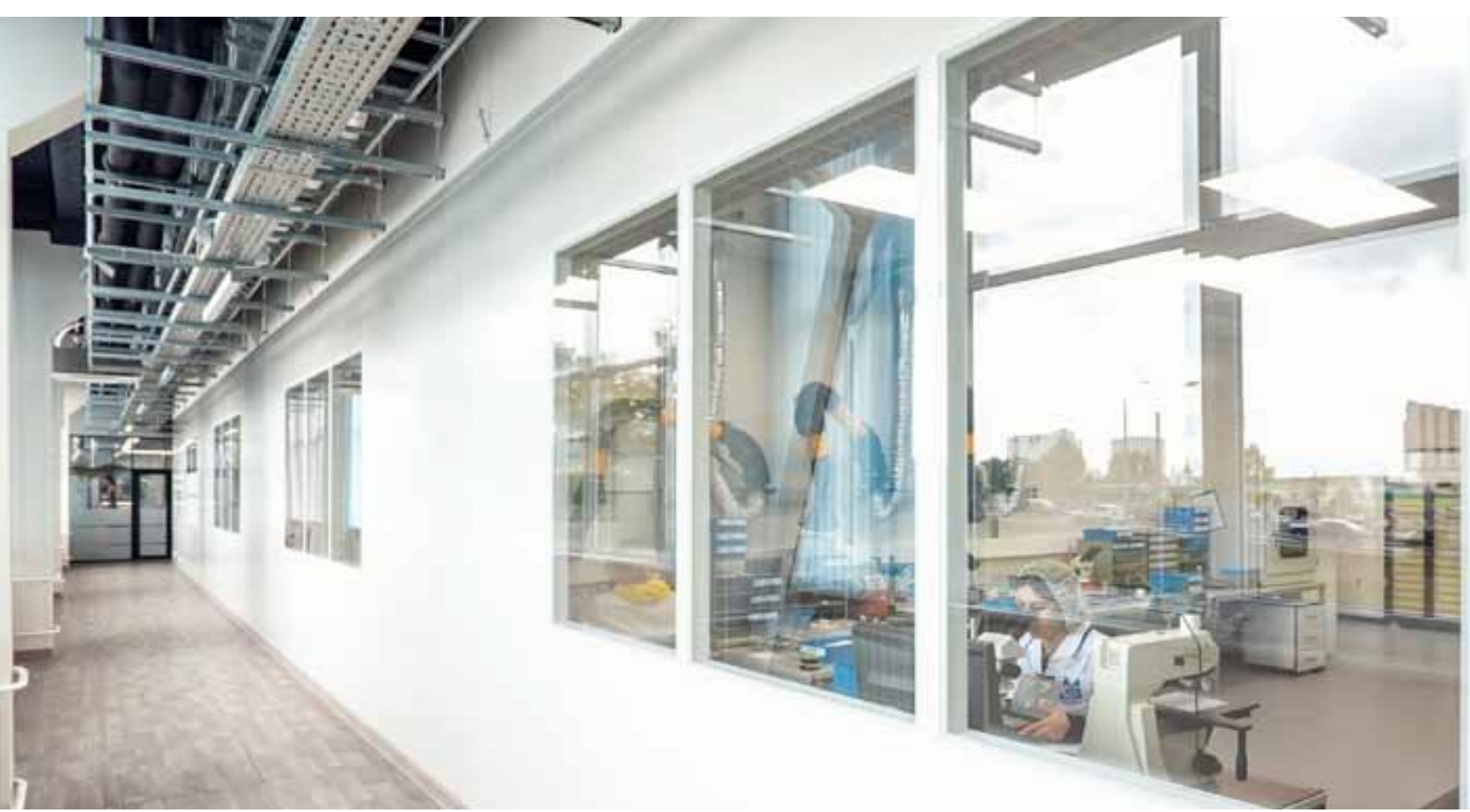

Компания "Микроволновые системы» была организована в 2004 году. В настоящее время предприятие проектирует, собирает и настраивает современные СВЧ-модули. Продолжая заниматься традиционной для себя тематикой - широкополосными СВЧ-усилителями мощности и малошумящими усилителями - компания расширяет спектр своей деятельности. Так, она взялась за разработку АФАР, осваивает цифровую обработку радиолокационных сигналов, производит мощные импульсные СВЧ-транзисторы. Активно развивается и производственная база предприятия. Пережив несколько переездов, центральный офис компании и ее производство обосновались в деловом центре "Сокол" на востоке Москвы, где уже более двух лет расширяют свои площади, вводя в строй новое технологическое и испытательное оборудование.

Мы посетили московскую площадку предприятия, где руководители и специалисты компании познакомили нас с производством и рассказали о достигнутых успехах и планах дальнейшего развития. Первым нас встретил в своем кабинете один из основателей компании, заместитель генерального директора, главный конструктор Андрей Александрович Кищинский. 
Андрей Александрович, с нашей последней встречи прошло два года. Какие события в жизни компании, случившиеся за это время, вы бы выделили?

На самом деле, событий произошло достаточно много. Мы решительно расширяем охватываемую компанией тематику, при этом оставаясь в рамках СВч-электроники. Если традиционно мы решали узкие задачи - занимались разработкой и производством модулей усилителей мощности, малошумящих усилителей, которые, кстати, завоевали большую популярность в нашей стране, то сейчас мы пошли как вглубь, в сторону компонентной базы, так и вверх к конечным изделиям. Так, в начале года мы создали обособленное подразделение в Саратове, которое занимается разработкой мощных миниатюрных импульсных усилителей на наших же СВЧ-элементах, приемо-передающих модулей радиолокационных диапазонов X и Ku. А этим летом в Нижнем Новгороде было образовано обособленное подразделение - дизайнцентр по разработке СВч ИС на основе GaAs и GaN.

Мы взялись за работу в области радиолокации на уровне почти законченного радиолокатора. Осваиваем вопросы первичной цифровой обработки радиолокационных сигналов.

Отдельное направление нашей деятельности, которое также активно развивается, - производство мощных импульсных СВЧ-транзисторов, аналогов зарубежных изделий компании Toshiba, которые уже находят применение в отечественной технике. Мы не обладаем собственным кристальным производством, поэтому работаем по схеме fabless, но мы являемся владельцем данных разработок, КД на эти изделия создается полностью у нас.

Кроме того, мы расширяем наши площади. К концу года они увеличатся в полтора раза.

В частности, недавно было выделено новое помещение для испытательной лаборатории электронных компонентов, к обустройству которой мы уже приступили. Там уже введена в эксплуатацию станция зондового тестирования ИС. В отдельно стоящем здании мы разместили вибростенд. Сейчас закупаем камеры влаги. Также в настоящее время выполняется пусконаладка новой установки герметизации ИС вакуумной пайкой, разработанной по нашему заказу. То есть на новых площадях у нас образуется некий "кластер» по производству и испытаниям ИС.

В целом ряде изделий мы уже перешли на использование собственных GaAs-транзисторов. Серийно сейчас применяется пять типов таких приборов, а разработано их порядка 30. На следующий год у нас запланирована работа с ФГБУ “ВНИИР» (ранее ФГУП «МНИИРИП») с тем, чтобы разработке транзисторов придать статус инициативной работы и тем самым дать возможность широкому спектру потребителей применять эти изделия.

Еще одна интересная работа, которая ведется в рамках задания Минпромторга России, - создание совершенно новой малогабаритной антенной решетки с 256 элементами размером всего около $15 \times 15$ см, которую в дальнейшем планируем предложить также и рынку - для исполь-

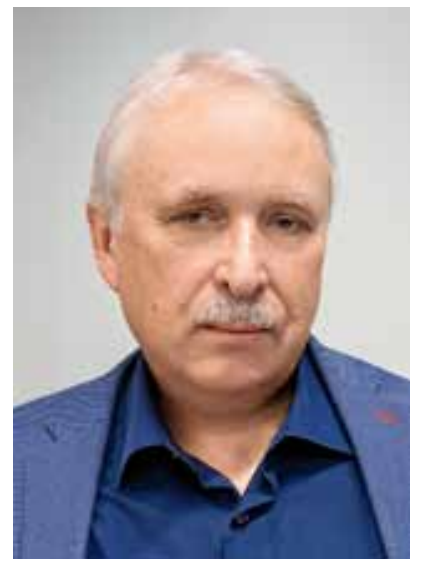

Андрей Кищинский

зования, например, в малой гражданской авиации. Также в наших планах сделать АФАР «эконом-класса», в разы дешевле тех, которые сейчас применяются в радиолокации

Вы сказали, что работаете по схеме fabless. А где вы размещаете кристальное производство, в России или за рубежом?

Пока преимущественно за рубежом. На текущий момент мы работаем с тремя фабриками в Юго-Восточной Азии, однако по некоторым, сравнительно несложным, проектам мы ведем переговоры с АО "Светлана-Рост» по арсенид-галлиевым технологиям и с томским НИИПП по диодным технологиям.

\section{Есть ли другие СвЧ-фабрики в России?}

Я перечислил, пожалуй, всех, кто сейчас может производить продукцию по заказам fabless-дизайнеров, за разумные деньги и в разумные сроки. Есть, конечно, и другие производства, но они либо отстали от времени, либо активно развиваются, но еще не наработали достаточных компетенций для работы в качестве foundry.

Нужно отметить, что в области производства СВЧ ЭКБ - GaAs- и GaN-технологий - намечаются сложности, подобные тем, с которыми столкнулись потребители кремниевых полупроводниковых компонентов. Пока кризиса здесь нет, но тенденция негативная: удлиняются сроки поставки, наблюдается перегрузка отдельных участков. Например, если на фабрике заказываешь полупроводниковую пластину, вероятно, будет желание разложить кристаллы в гель-тару. Эта операция сравнительно недорогая. Но стоит указать её, как срок поставки резко удлиняется.

Есть ли способы производить СВЧ-кристаллы на кремниевом производстве? Может быть, это придало бы 
некую гибкость и увеличило бы возможности по изготовлению СВЧ ЭКБ в России?

В общем случае, такой возможности нет. Арсенид галлия и нитрид галлия на карбиде кремния на этих линиях делать нельзя совсем. Есть единственная технология, относительно которой существует мнение, хотя и спорное, что это возможно, - нитрид галлия на кремнии. В силовой электронике это совместили: на больших пластинах кремния формируют пленки GaN путем эпитаксии через буферные слои, и на этих пластинах формируют элементы на тех же линиях, что используются для изготовления кремниевых кристаллов по микронным и субмикронным технологиям. Но в области СвЧ организовать промышленное производство ИС нитрида галлия на кремнии удалось лишь нескольким компаниям в мире, и не на стандартном кремниевом производстве, а на специализированных технологических линиях.

В целом, нитрид галлия на кремнии - хорошее, перспективное направление. О нем много говорят, в частности у нас, в Зеленограде. Но целесообразно ли ставить эту технологию для производства СВЧ-изделий на существующих кремниевых фабриках - всё же вопрос, на который я бы дал скорее отрицательный ответ.

Как бы вы охарактеризовали рынок СвЧ-электроники в России в целом?

Это одна из "живых" и растущих областей. Хотя существуют определенные сложности, в большей мере касающиеся организационных вопросов, задач для нас становится всё больше, они всё более интересные. Это, конечно, дает стимул для развития нашей компании.

Рассказ Андрея Александровича Кищинского дополнил генеральный директор АО "Микроволновые системы» Сергей Алексеевич Исаев.

Сергей Алексеевич, в условиях активного расширения компании, о котором говорил Андрей Александрович, где вы находите новые кадры?

Кадры - это одна из главных проблем нашей отрасли. Особенно сильно мы ее ощущаем здесь, в Москве. К сожалению, хорошие специалисты часто уходят в другие сферы, например в ИТ.

Мы привлекаем к работе специалистов в том числе из регионов. Внимательно отслеживаем, кто покидает ту или иную компанию.

Чем вы заинтересовываете специалистов? Почему они уходят из компаний, где они работали, и приходят к вам?

Прежде всего, отмечу, что мы ни разу не переманили сотрудников у наших коллег: абсолютно все специалисты с опытом, пришедшие к нам, уволились со своего

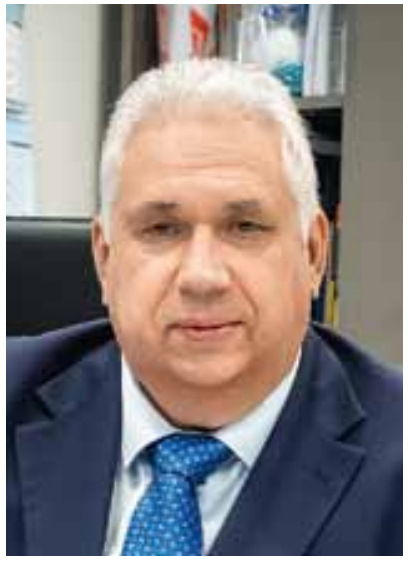

Сергей Исаев предыдущего места работы сами, и лишь после этого мы предложили им присоединиться к нашей команде. А причины их ухода могут быть разными - от неудовлетворительного для них уровня зарплаты до разногласий с технической политикой предприятия.

Конечно, мы заинтересовываем сотрудников материально, и это может выражаться не только в зарплате как таковой.

Например, если сильный, зарекомендовавший себя специалист приезжает к нам в Москву из другого региона, мы содействуем его обустройству на новом месте. Но, конечно, это затратный вариант. Поэтому нам интереснее развивать наши региональные подразделения.

И само собой, важным стимулом для настоящего специалиста является профессиональный рост. Хотя решающее слово о том, какую тему брать, а какую нет, остается за центральным офисом, наши региональные подразделения достаточно самостоятельны в создании и разработке новых тематик. Некоторые их сотрудники достаточно быстро набирают компетенции, чтобы стать главными конструкторами направлений.

И для нас это очень важно. Как сказал Андрей Александрович, сейчас много интересных и перспективных задач. Но для их решения всегда не хватает ресурсов, и в нашем случае это не столько финансовые ресурсы, сколько человеческие. Благодаря тому, что новые сотрудники растут профессионально, берут в свои руки новые тематики, наша компания может развиваться и расширять область своей деятельности.

Мы услышали о том, как развивалась компания в последние годы. Расскажете о планах на ближайшее будущее?

Сейчас одна из основных задач - усиление наших региональных подразделений. Как уже было сказано, в этом году мы создали два таких подразделения - в Саратове и Нижнем Новгороде. На данный момент мы открываем подразделение в Санкт-Петербурге. Задумываемся о Томске.

По мере развития обособленных подразделений и профессионального роста их команд, я думаю, мы будем наделять их все большей самостоятельностью. Нам важно, чтобы работы, за которые мы беремся, выполнялись вовремя, а сроки заказчики нам устанавливают крайне сжатые. И вероятно, бо́льшая самостоятельность наших 
подразделений послужит повышению эффективности работы, а следовательно, соблюдать сроки станет легче

Конечно же, в наши планы входит дальнейшее расширение нашего производства и возможностей по испытаниям, поэтому мы расширяем площади и набираем сотрудников и сюда, на московскую площадку.

А что уже удалось сделать здесь, вы сейчас сами увидите.

О начальных этапах создания СВЧ-модулей - схемотехническом и конструкторском проектировании - нам рассказал ведущий конструктор проектного отдела Сергей Викторович Гармащ.

\section{Сергей Викторович, с чего начинается разработка нового прибора?}

С технического задания, которое нам предоставляет заказчик. Конечно, он предварительно согласует с нами проект Т3. На этом этапе у нас могут возникнуть замечания, поскольку иные требования заказчика могут вызывать необоснованные проблемы при реализации проекта, а порой бывают просто невыполнимыми технически. Например, в одной работе была задана очень высокая выходная мощность разрабатываемого усилителя. В процессе взаимодействия с заказчиком выяснилось, что от нашего усилителя к антенне проложен длинный кабель, в котором возникают большие потери мощности. Оказалось, его можно сделать короче, и тем самым снизить требуемую выходную мощность.

Вы проектируете электрическую схему изделия. Заказчику важно, что внутри прибора, или его интересует только конечный результат?

В основном его интересуют только параметры самого изделия, но в последнее время также предъявляются требования к используемой компонентной базе. Курс на импортозамещение диктует применение российских компонентов за исключением технически обоснованных случаев, и это требование прописывается в каждом Т3.

\section{Каково приблизительное соотношение отечественных} и импортных компонентов в ваших модулях?

Ответом на ваш вопрос может служить следующий пример: я только что закончил составлять перечень ЭКБ по одной из работ, и там получилось соотношение примерно 50/50. По сравнению с прошлыми годами доля отечественных компонентов становится больше, в нашей стране появляются новые конденсаторы, резисторы, чип-индуктивности, транзисторы, которые мы можем использовать. При этом основная часть отечественной ЭКБ приходится на низкочастотные узлы наших модулей, а вот в СВЧ-части преобладают импортные компоненты.

Но наша компания сама занимается импортозамещением СВЧ ЭКБ: в ее обособленных подразделениях ведется разработка СВЧтранзисторов на основе базовых структур фабрик, на которых впоследствии эти транзисторы изготавливаются. Хотя производство кристаллов выполняется в Юго-Восточной Азии, эти приборы признаются отечественными. То же касается СВЧ ИС, которые разрабатываются нашим предприятием и изготавливаются за рубежом.

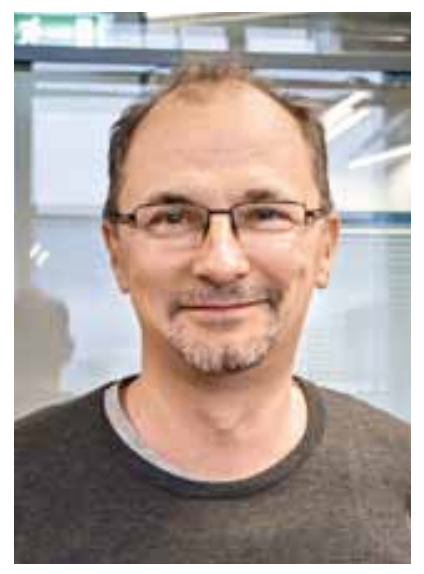

Сергей Гармаш

Насколько помогают симуляция и моделирование при разработке ваших изделий? Позволяют ли они снизить количество итераций изготовления опытных образцов?

Они играют важную роль. Средства моделирования в составе САПР позволяют повышать качество проектирования изделия, сокращая тем самым трудоемкость доводки проекта. Но чтобы их применение было эффективным, конечно, необходимы опыт и понимание того, что проектируешь, как правильно это делать, каким способом.

Моделирование также активно используется нашими коллегами из конструкторского отдела, которые воплощают разработанные нами принципиальные схемы и элементы СВЧ-топологии в конструкции изделий и создают КД, по которой уже выполняется производство продукции. В частности, инструменты САЕ очень помогают в расчете тепловых режимов в критичных случаях. Например, в ряде

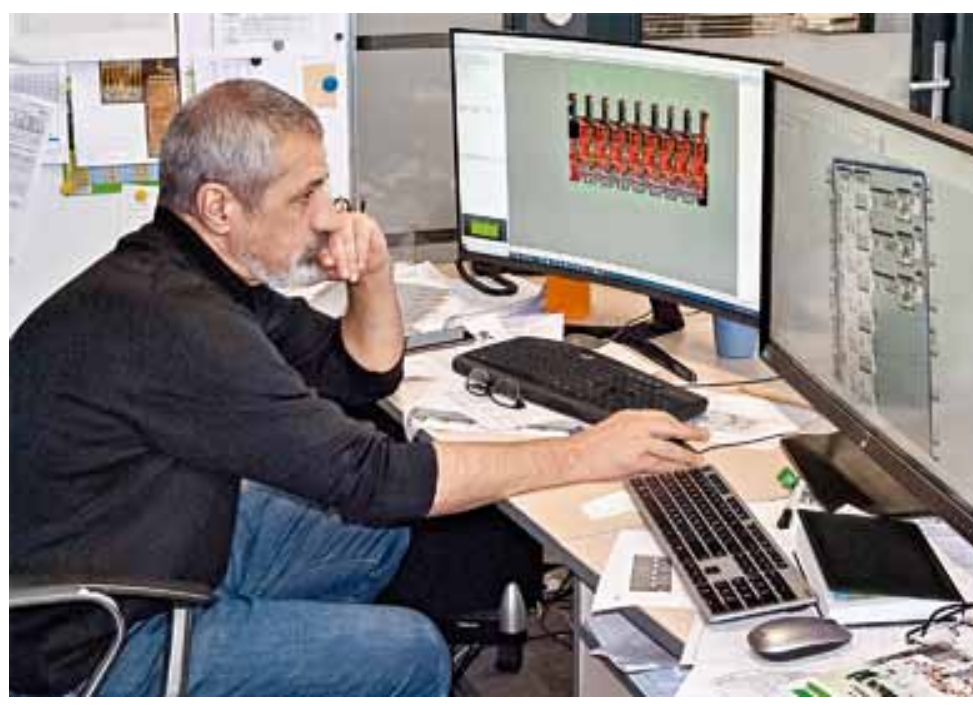

Процесс конструкторского проектирования: ведущий конструктор КБ Василий Смирнов за работой 
проектов, где применялось сочетание воздушного и жидкостного охлаждения, моделирование очень сильно упростило работу, и его результаты оказались достаточно близки данным, полученным на натурных испытаниях. Одной из немногих областей, где мы практически не используем моделирование, является расчет экранирования. Просто в этом пока нет необходимости: опыта наших специалистов вполне достаточно, чтобы подобрать параметры экранирования без привлечения специализированных программ.

Также отмечу, что у нас внедрена PDM-система, которая позволяет обмениваться документацией и согласовывать ее в электронном виде, ничего не печатая, а также обеспечивает групповую работу над изделием.

Познакомившись с проектированием СВЧ-модулей, мы отправились на сборочное производство предприятия. Нашим гидом выступил начальник производства Валерий Анатольевич Чиркин.

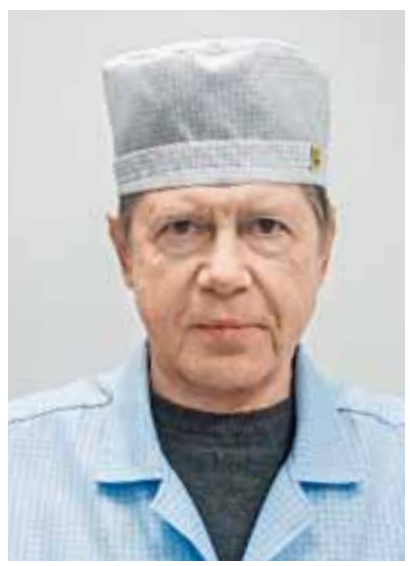

Валерий Анатольевич, СвЧ-электроника обладает своей спецификой. Предъявляются ли особые требования к коммутационным основаниям, платам, которые применяются в ваших модулях?

В наших модулях используются два типа коммутационных оснований: для низкочастотных частей, таких как, наприВалерий Чиркин мер, источники питания

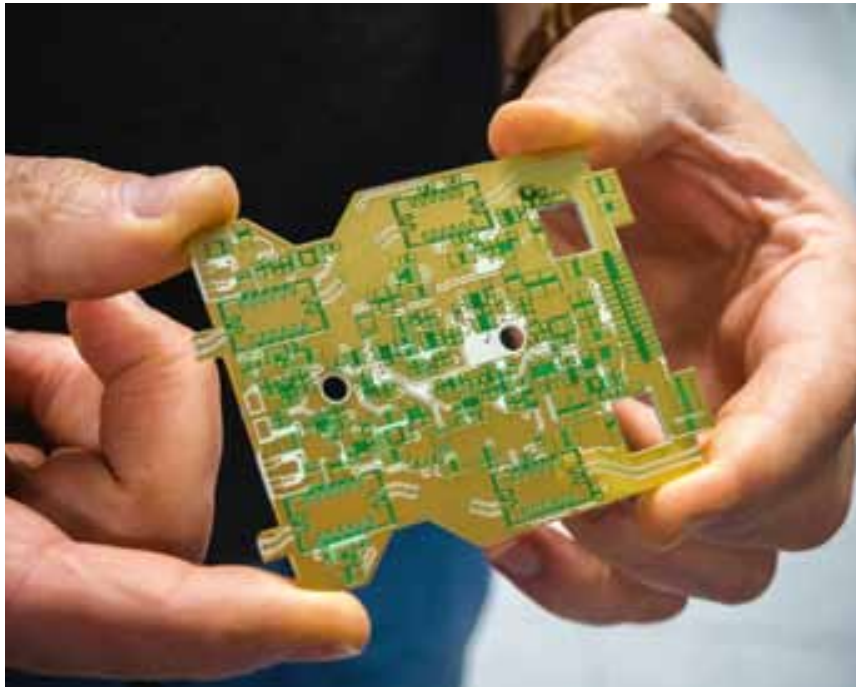

Печатная плата с СВЧ-слоями

или схемы управления, применяются обычные печатные платы, а в СВч-части - из высокочастотной керамики, поликора, полуизолирующего арсенида галлия. Низкочастотные узлы также могут содержать отдельные СвЧ-области. В этом случае в их структуру входят слои из высокочастотных материалов типа фторопласта.

\section{Высокочастотная керамика у вас российская?}

В основном, да. В нашей стране есть много компаний, обладающих таким производством. Однако для современных приборов нужны платы из поликора толщиной в четверть миллиметра и с зазорами, составляющими десятки, а иногда даже единицы микрометров. Такие зазоры могут обеспечить лишь немногие производители.

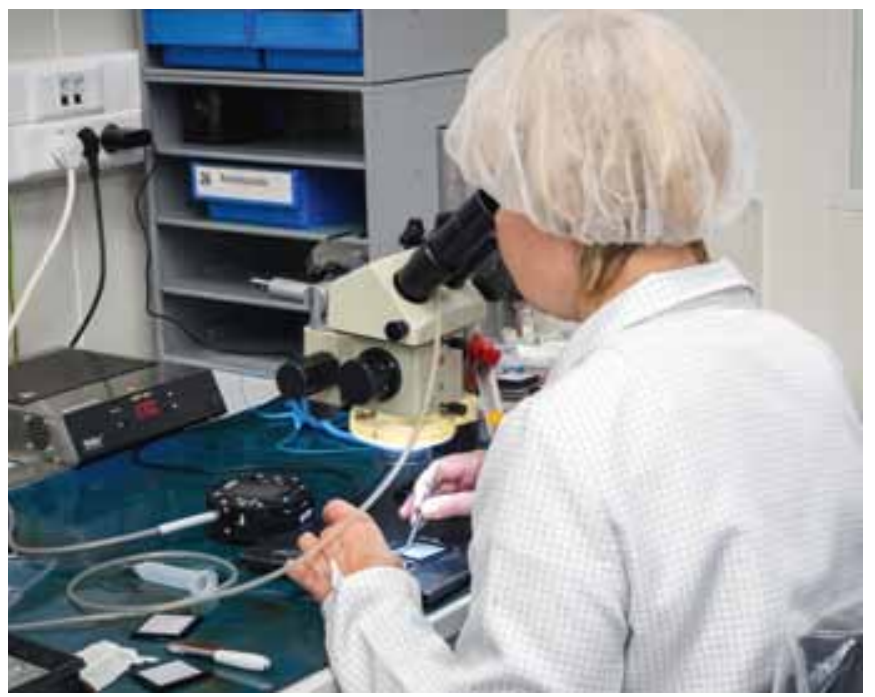

Монтаж SMD-компонентов на СBЧ-керамику 


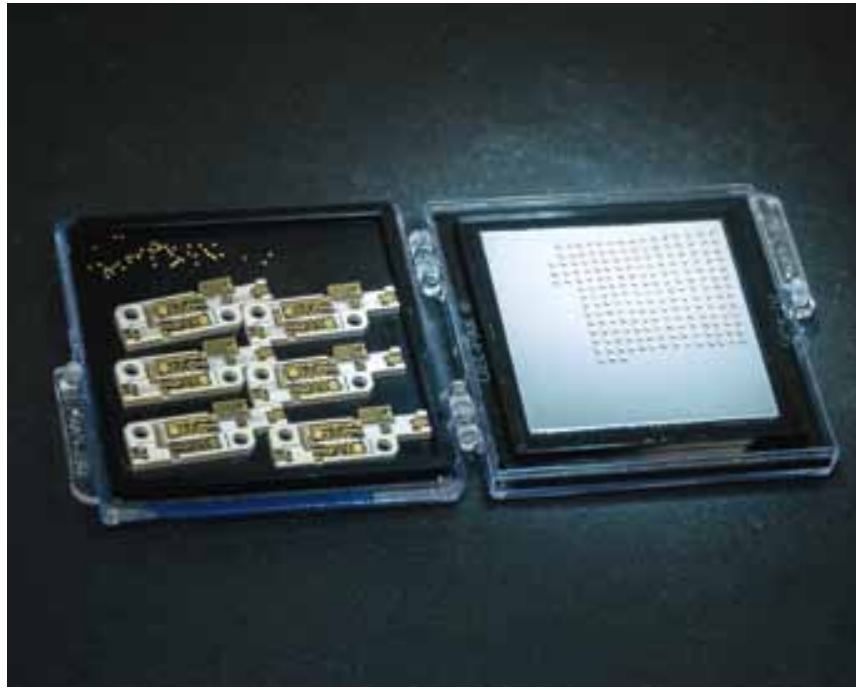

SMD-конденсаторы и керамические основания, на которые они монтируются

Также очень мало предприятий, которые способны выполнять качественную гальваническую металлизацию никелем, серебром, золотом. Выполнить декоративное покрытие могут многие, но найти тех, кто может обеспечить хорошую паяемость - непростая задача. Мы заказываем выполнение гальванических, а также лакокрасочных покрытий на одном предприятии в Сергиев-Посаде. Их качество нас устраивает.

\section{Как осуществляется монтаж компонентов на платы?}

Большинство компонентов монтируется по технологии поверхностного монтажа. Это в основном пассивные, а также низкочастотные активные компоненты. Сначала на контактные площадки через трафарет из нержавеющей стали наносится паяльная паста или токопроводящий клей, затем устанавливаются компоненты. Если монтаж производится на паяльную пасту, плата с компонентами отправляется в печь пайки оплавлением. В случае применения клея, его полимеризация выполняется в шкафах при повышенной температуре. Иногда на низкочастотных платах встречается и монтаж в отверстия, но в очень малых количествах.

SMD-монтаж производится полностью вручную, поскольку партии у нас небольшие и применение автоматического оборудования неоправданно.

Другой вид монтажа, который присутствует в наших изделиях, - проволочная разварка. Этим способом устанавливаются бескорпусные кристаллы как непосредственно на платы и подложки, так и на рамки. Здесь речь идет об изделиях очень малых размеров. Например, мы монтируем кристаллы GaAs-транзисторов с размерами всего 0,3×0,5 мм, а проволока, обеспечивающая электрические соединения, имеет диаметр 20 мкм.
Отмечу, что SMD-монтаж СВЧ-узлов выполняется в том же помещении, что и монтаж кристаллов с проволочной разваркой, где обеспечен необходимый уровень чистоты, а монтаж низкочастотных плат осуществляется в отдельном цехе.

Также у нас применяется эвтектическая пайка, но в небольших количествах. Ее применение мы будем расширять, поскольку она обеспечивает лучший теплоотвод от кристалла.

Могут ли на одной плате присутствовать компоненты, установленные на пасту и на клей?

Нет, для каждого узла мы выбираем только один способ монтажа SMD-компонентов, исходя из требований к ним, а также нашего опыта. Проход узла и через печь, и через шкаф отверждения клея ухудшает его свойства. Да и просто это неэффективно.

\section{На каком оборудовании выполняется проволочная разварка?}

Для этого у нас есть два типа установок термозвуковой сварки: методом "клин-клин» и "шарик-клин» соответственно. Одна из них совсем новая - ее мы приобрели всего месяц назад. Это тоже не автоматические установки.

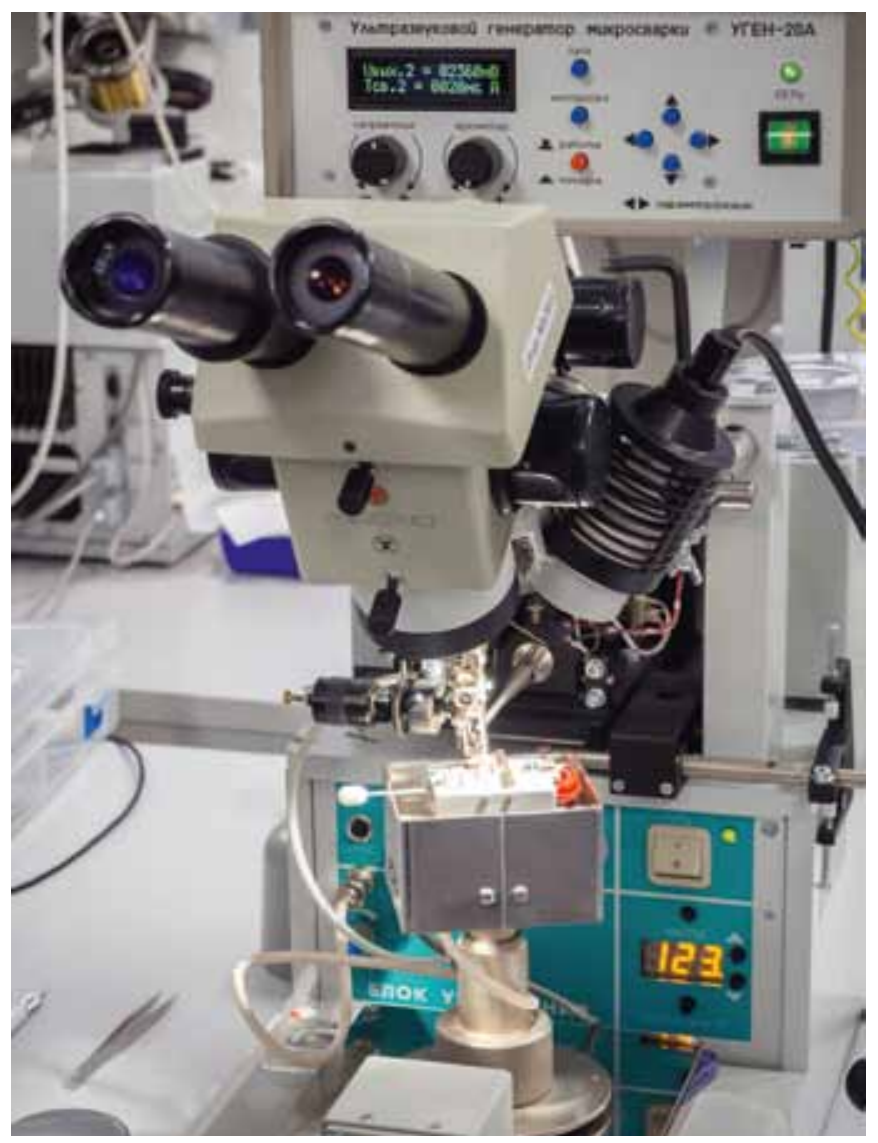

Установка проволочной разварки 


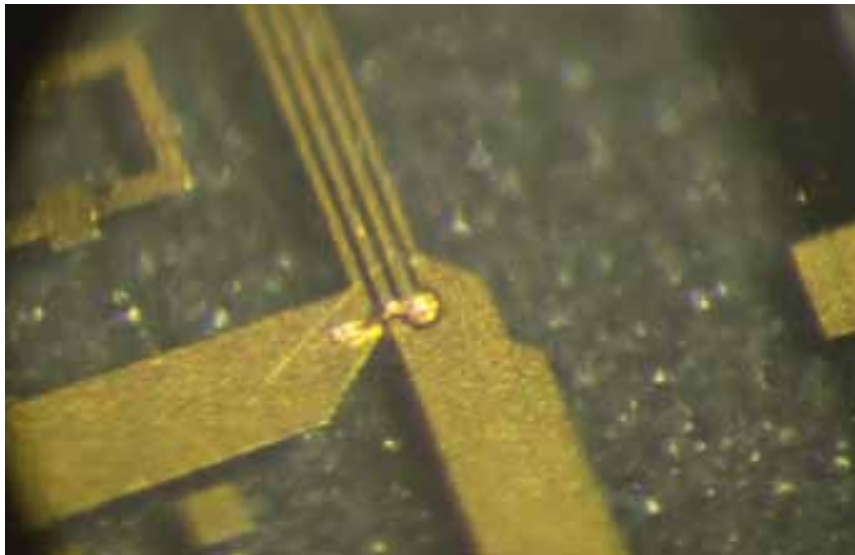

Проволочная перемычка (микрофотография)

Но объемы производства у нас растут, и со временем нам придется задуматься о том, чтобы автоматизировать эту операцию.

Мы выполняем различные типы соединений с помощью Уз-сварки, а не только проволочную разварку между двумя точками. Например, проволока может соединять несколько контактных площадок, "перепрыгивая" через дорожки. Или другой пример: в одном из наших изделий некоторые контактные площадки транзисторов

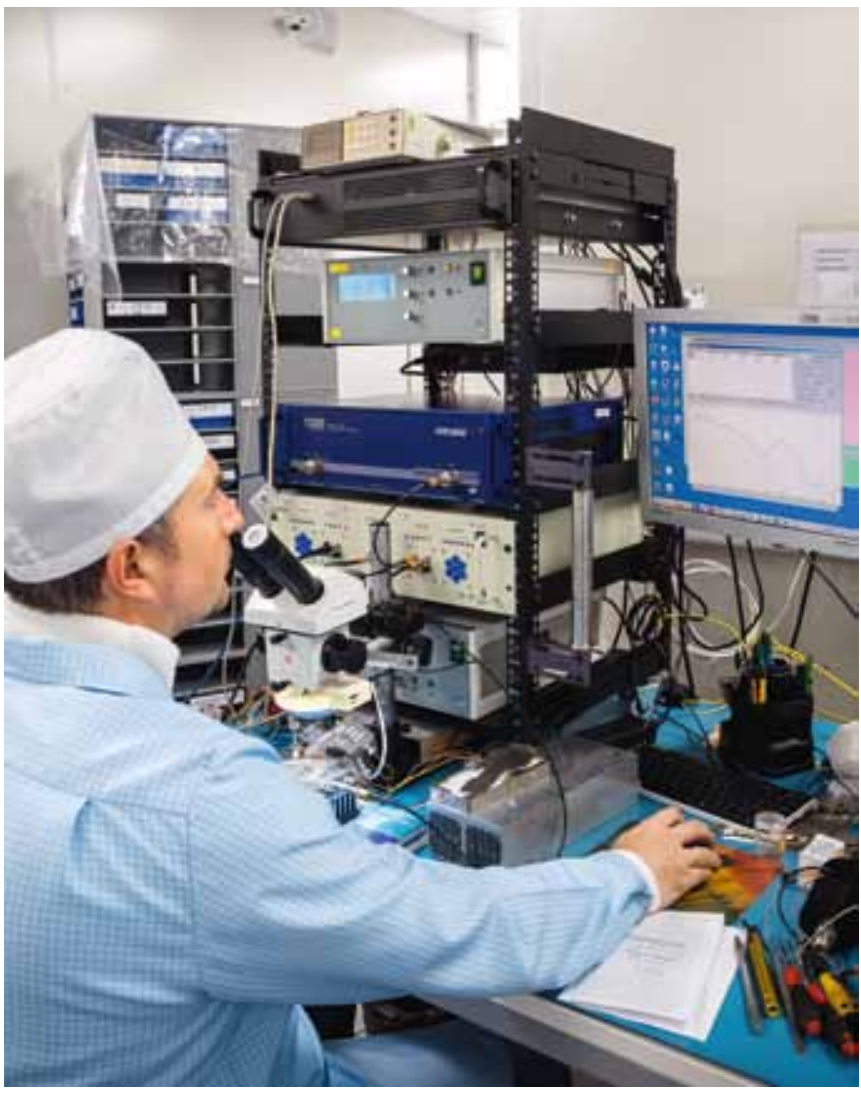

Рабочее место настройки и регулировки

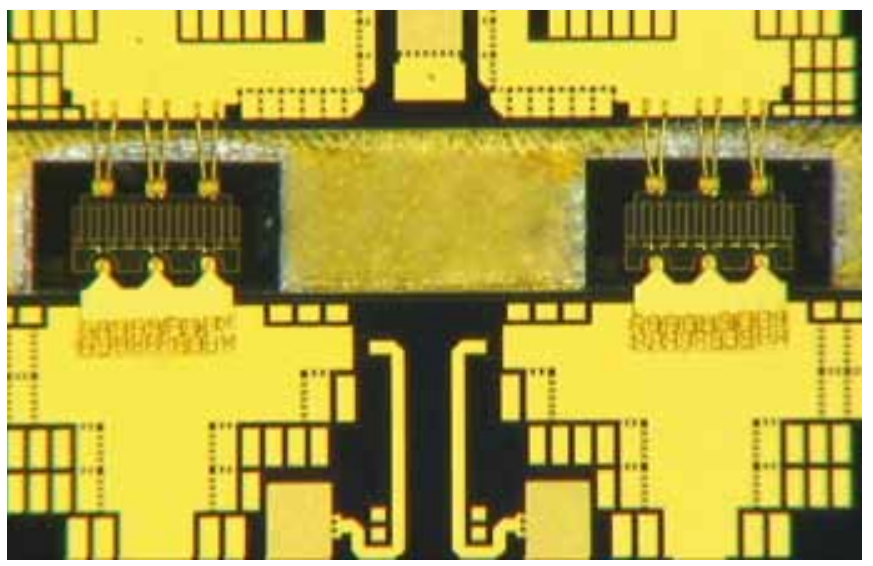

Транзистор, приваренный на балках (микрофотография)

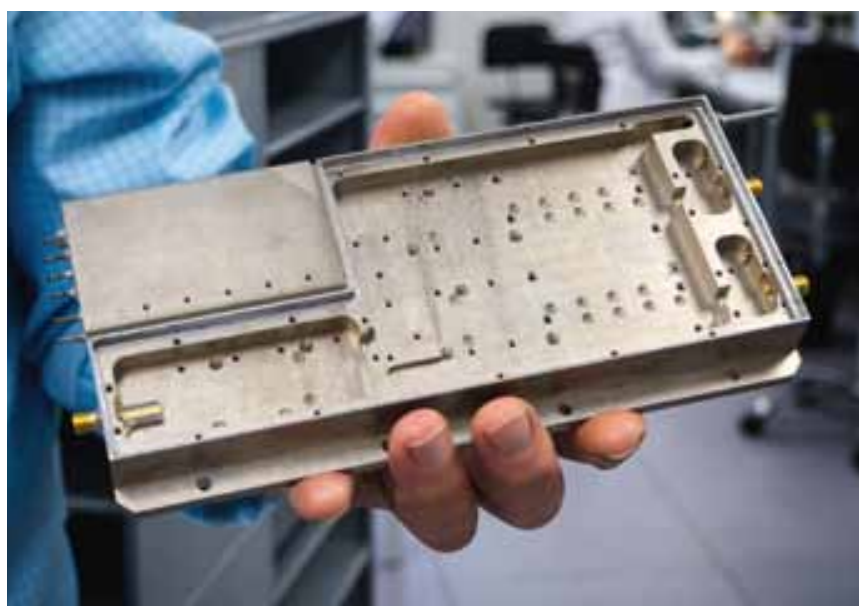

Корпус СвЧ-модуля. В правом верхнем углу видна трубка для откачки воздуха и заполнения азотом герметичной части

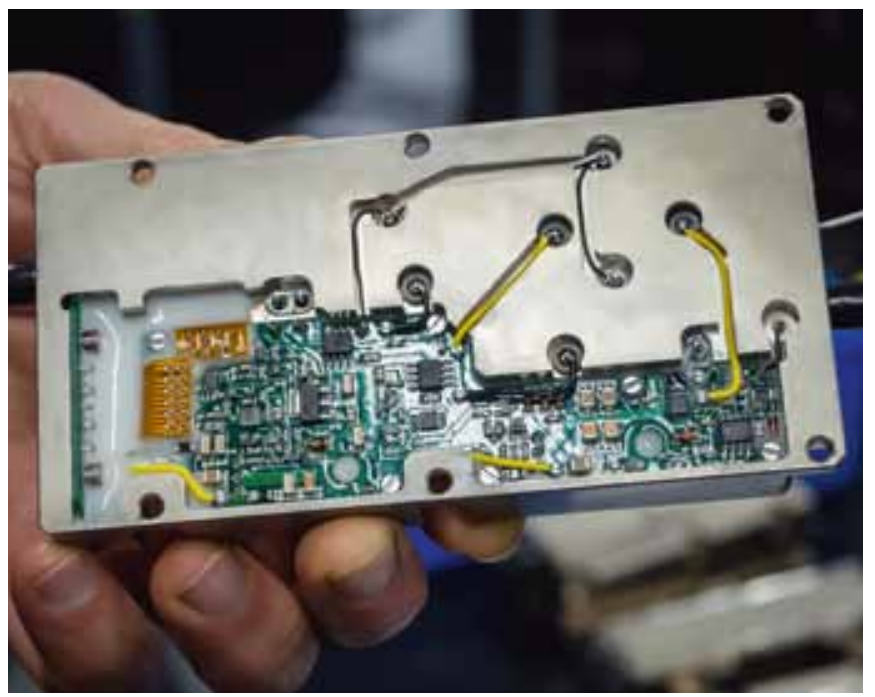

Корпус с установленным низкочастотным узлом 
привариваются к балке, выступающей с соседней платы

Какие операции выполняются после того, как узлы модуля собраны?

Далее осуществляется настройка и регулировка узлов. СВЧ-устройства - вещь очень тонкая. Небольшой зазор, изменение длины проволоки или отклонение ширины полоска - и параметры могут очень сильно "уплыть». Есть устройства, выход годных которых после сборки составляет всего порядка 60\%, а остальные необходимо настраивать.

Настройка и регулировка выполняется на универсальных автоматизированных стендах. Если выявляются отклонения в параметрах, выполняется коррекция путем установки перемычек или их удаления. Это

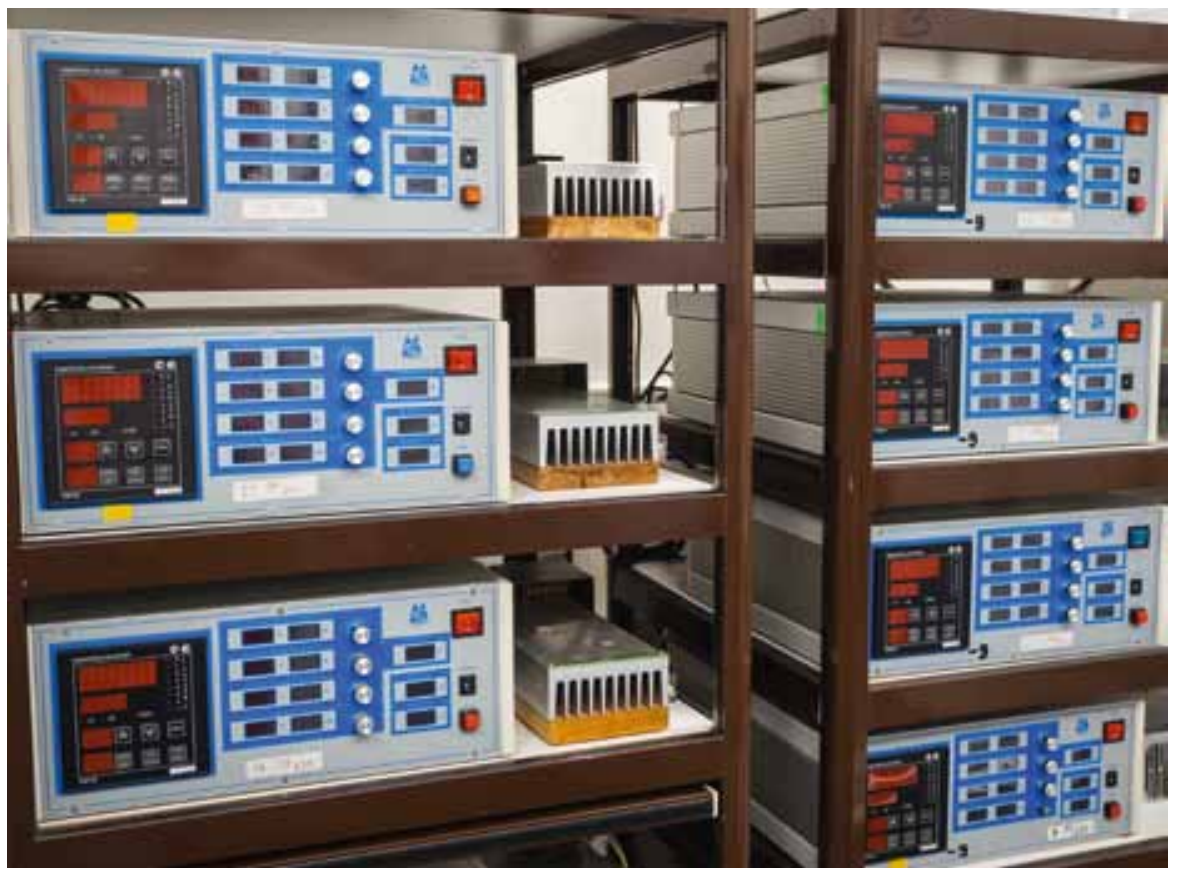
очень кропотливая, ювелирная работа.

Затем выполняется сборка изделия в корпус. Металлические корпуса мы получаем от наших поставщиков, которые изготавливают их на станках с чПУ по нашим чертежам. Также выполняется электрический монтаж узлов в корпусе. Иногда плата припаивается к корпусу всей плоскостью, а когда площадь паяного соединения

большая, высока вероятность образования пустот. Поэтому при запуске новых изделий мы передаем первые образцы нашему партнеру из Зеленограда, который выполняет рентген-контроль паяных соединений. А при уже отработанной технологии качество пайки как в рамках узла, так и при монтаже в корпус мы проверяем с помощью микроскопа.
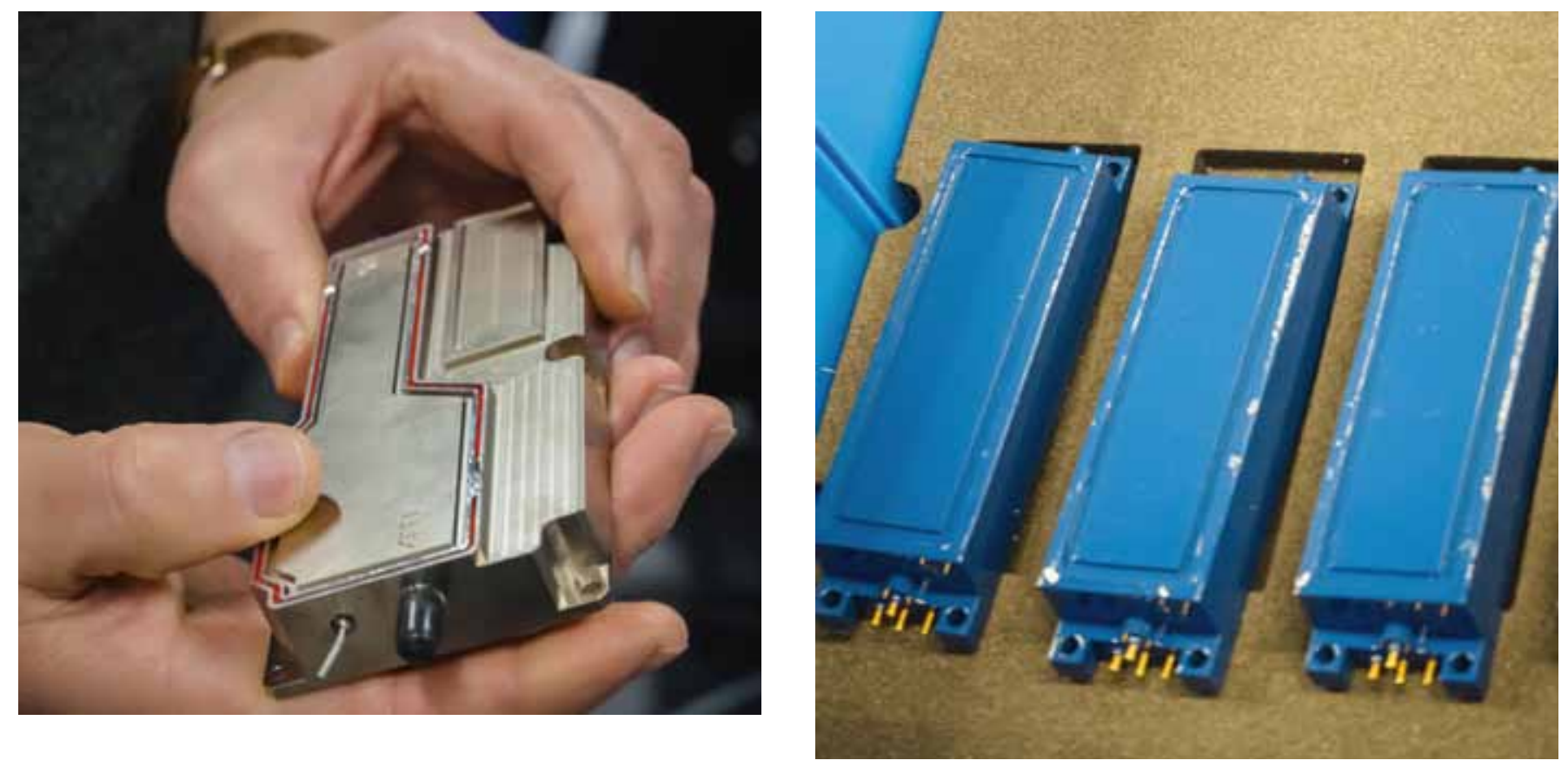

Модуль с установленной крышкой. По контуру крышки виден фторопластовый уплотнитель

Готовые модули перед маркировкой 


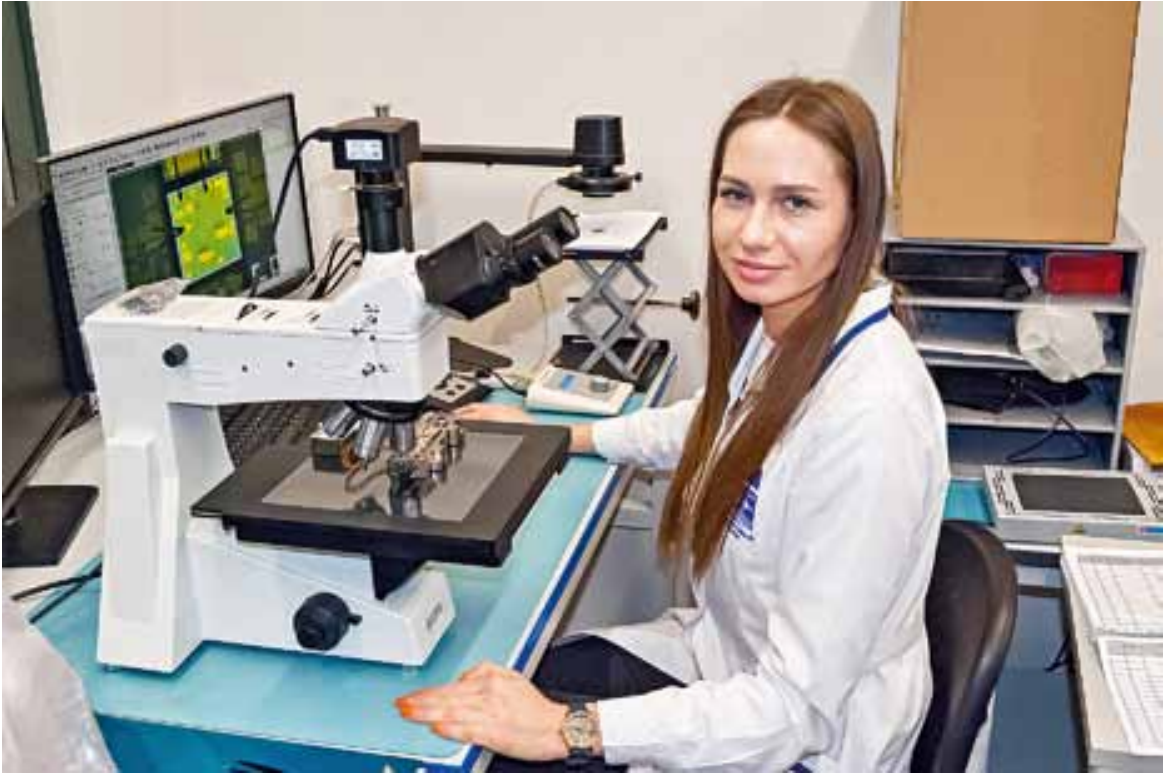

В отделе технического контроля

\section{Как модули защищаются от внешних воздействий?}

Обычно корпус модуля разделен на две части. Одна из них - полностью герметичная, в ней располагается СвЧ-электроника. После установки СВЧ-узлов эта часть закрывается крышкой с уплотнителем

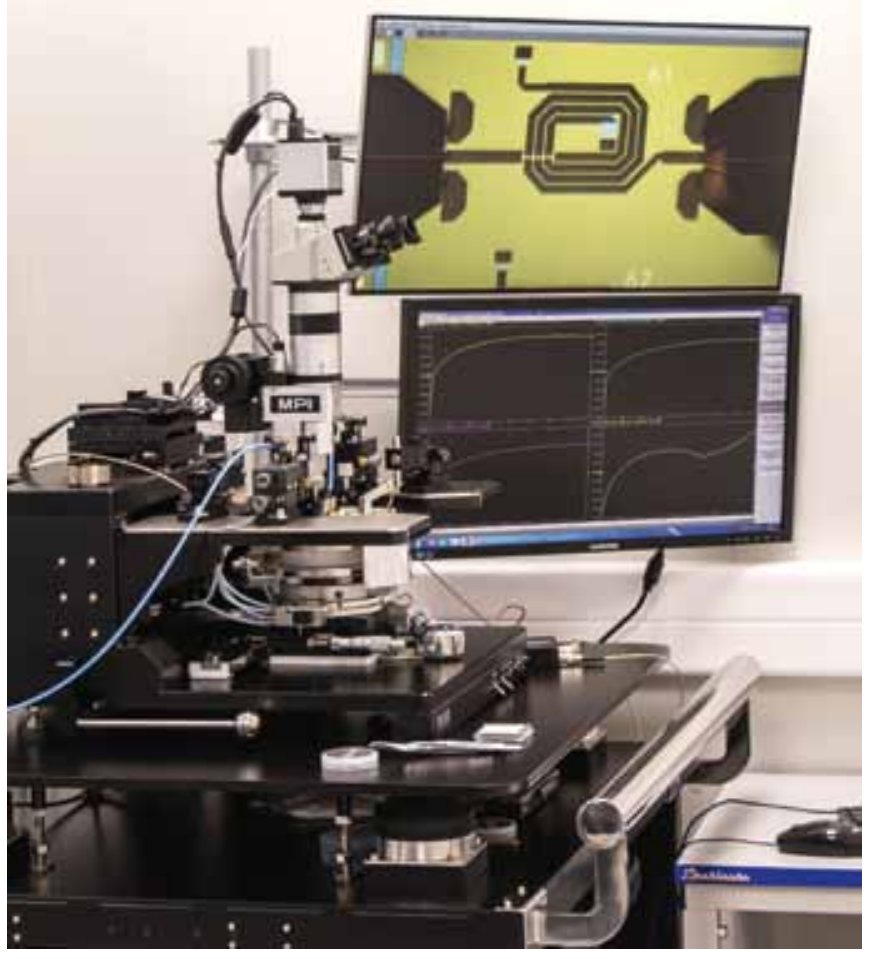

Установка зондового тестирования из фторопласта. Крышка запаивается по контуру. Уплотнитель нужен для того, чтобы, если изделие потребуется отремонтировать, можно было снять крышку, предварительно удалив припой. Затем из герметичного объема откачивается воздух через специальную трубку, предусмотренную на корпусе, и этот объем заполняется азотом, а трубка пережимается.

Защита второй части модуля осуществляется компаундом.

Отмечу, что перед герметизацией и заливкой компаундом устройства проходят электротермотренировку, где работают непрерывно 96 ч под нагрузкой, а после окончательной сборки они проходят проверку герметичности, термоциклирование в течение 12 ч в камерах тепла и холода, а также испытания на вибростенде.

На каких этапах выполняется контроль качества, кроме конца маршрута, когда изделия практически готовы?

По всему технологическому маршруту есть контрольные точки, в которых проверка является обязательной, но если у нас возникают какие-либо сомнения в качестве, то мы осуществляем контроль и вне этих точек. Наш ОТК выполняет большое количество разнообразных проверок-от контроля качества пайки до выявления царапин на покрытиях и дефектов золотых проводников. Для этого применяется оптический микроскоп с цифровой матрицей, обеспечивающий большое увеличение и высокое качество изображений. Он позволяет выявлять дефекты, которые в простой микроскоп сложно увидеть, и, кроме того, фотографировать изделия для составления отчетов.

Кстати, здесь стоит вернуться к началу маршрута и поговорить о входном контроле. У нас эта функция закреплена также за отделом ОТК, который тщательно проверяет все поступающие на наше производство изделия и корпуса, и электронные компоненты, и платы.

А недавно мы организовали небольшой участок $30 \mathrm{H}^{-}$ дового тестирования, где выполняется контроль параметров кристаллов, в том числе и СВч, до их монтажа. Это важная операция, позволяющая отсеивать компоненты, в надежности которых мы не уверены. Ведь надежность наших модулей зависит как от нашей работы, так и от качества комплектующих.

Спасибо за интересный рассказ. 


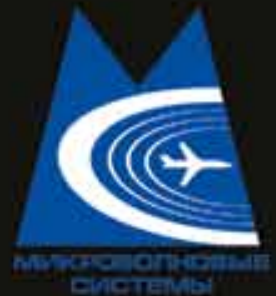

ИНТЕЛЛЕКТ. КАЧЕСТВО.

АО «МИКРОВОЛНОВЫЕ СИСТЕМЫМ Москва, Щелковское шоссе, А.5, стр.1 Ten. (499) 644-21-03, (499) 644-25-62 (многоканальный) Факс + 7(499) 644-19-70

E-mail:mwsystems@mwsystems.ru www.mwsystems.ru

- СОВРЕМЕННОЕ ПРОИЗВОДСТВО И ТЕХНОЛОГИИ

- OПТИМАЛЬHОЕ СООТНОШЕНИЕ ЦЕНА/КАЧЕСТВО

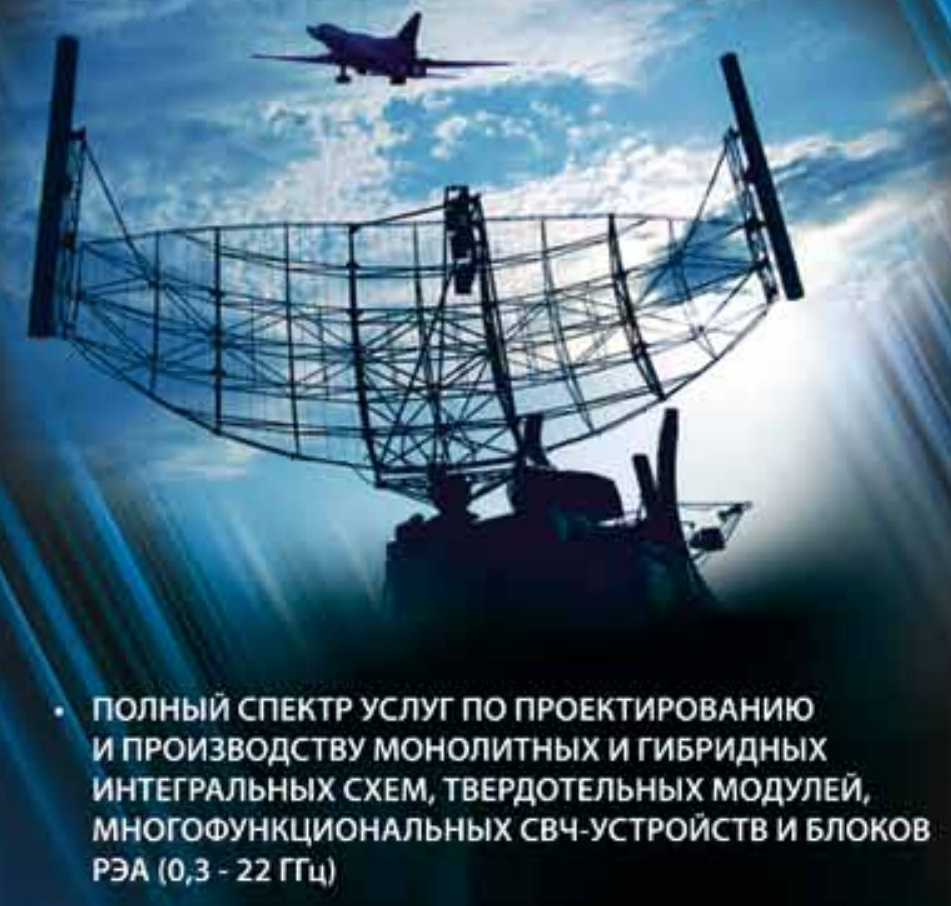

ПОЛНЫЙ СПЕКТР УСЛУГ ПО ПРОЕКТИРОВАНИЮ И ПРОИЗВОДСТВУ МОНОЛИТНЫХ И ГИБРИДНЫХ МНОГОФУНКЦИОНАЛЬНЫХ СВЧ-УСТРОЙСТВ И БЛОКОВ PЭA $(0,3$ - 22 TrL $)$

\section{АКЦИОНЕРНОЕ ОБЩЕСТВО «МИКРОВОЛНОВЫЕ СИСТЕМЫ"}
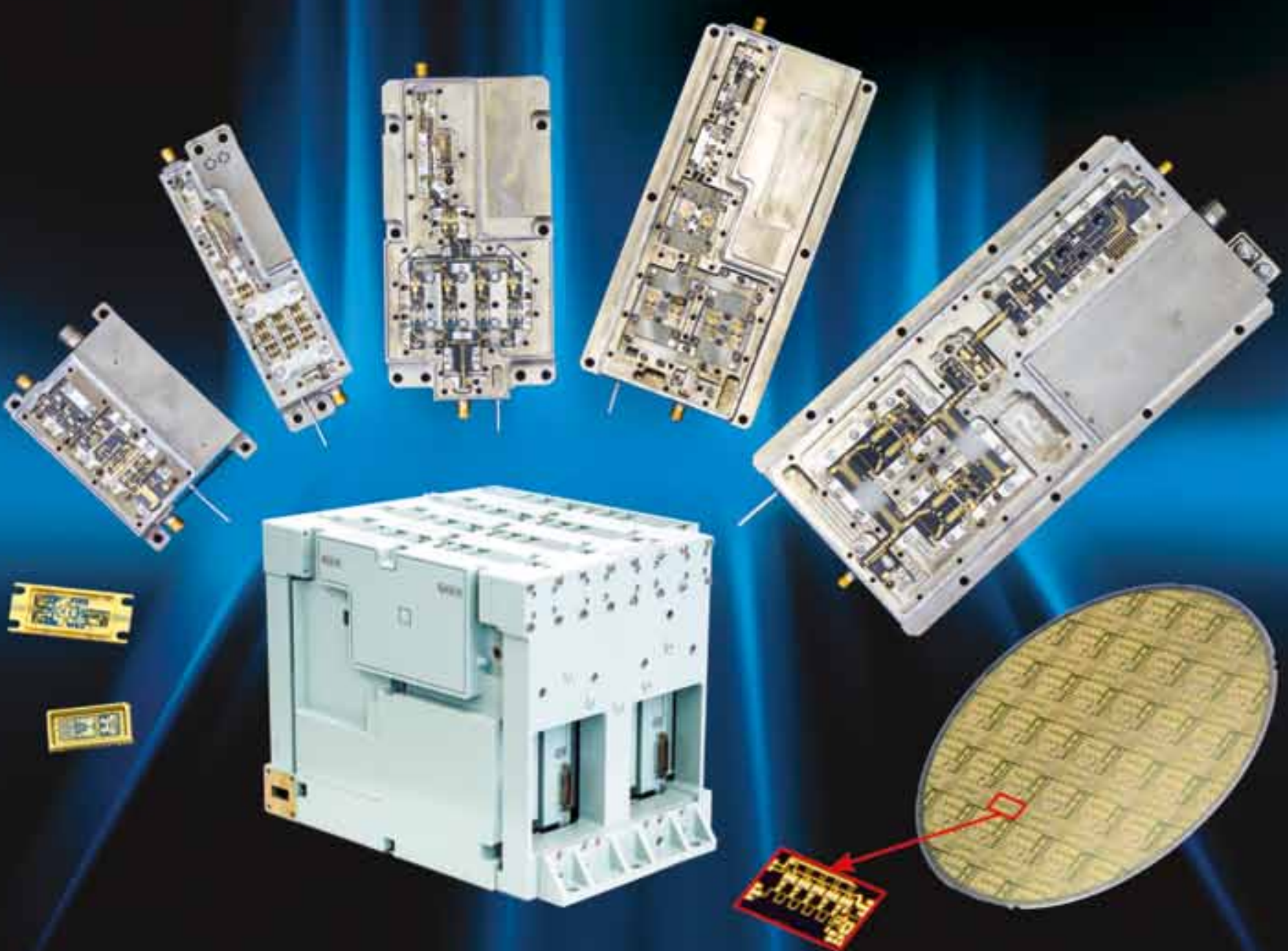